\title{
Efficacy of radiosensitizing doped titania nanoparticles under hypoxia and preparation of an embolic microparticle
}

This article was published in the following Dove Press journal:

International Journal of Nanomedicine

18 May 2017

Number of times this article has been viewed

\author{
Rachel A Morrison 1,* \\ Malgorzata J Rybak-Smith ${ }^{1, *}$ \\ James MThompson ${ }^{2}$ \\ Bénédicte Thiebaut ${ }^{3}$ \\ Mark A Hill ${ }^{2}$ \\ Helen E Townley ${ }^{1,4}$ \\ 'Department of Engineering Science, \\ ${ }^{2}$ Gray Laboratories, CRUK/MRC \\ Oxford Institute for Radiation \\ Oncology, University of Oxford, \\ Oxford, ${ }^{3}$ Johnson Matthey, Technology \\ Centre, Reading, Berkshire, ${ }^{4}$ Nuffield \\ Department of Obstetrics and \\ Gynaecology, John Radcliffe Hospital, \\ University of Oxford, Oxford, UK
}

*These authors have contributed equally to this work
Correspondence: Helen E Townley Nuffield Department of Obstetrics and Gynaecology, Oxford University, John Radcliffe Hospital, Oxford, OX3 9DU, UK

Email helen.townley@eng.ox.ac.uk
Abstract: The aim of this study was to develop a manufacturing protocol for large-scale production of doped titania radiosensitizing nanoparticles (NPs) to establish their activity under hypoxia and to produce a multimodal radiosensitizing embolic particle for cancer treatment. We have previously shown that radiosensitizing NPs can be synthesized from titania doped with rare earth elements, especially gadolinium. To translate this technology to the clinic, a crucial step is to find a suitable, scalable, high-throughput method. Herein, we have described the use of flame spray pyrolysis (FSP) to generate NPs from titanium and gadolinium precursors to produce titania NPs doped with 5 at $\%$ gadolinium. The NPs were fully characterized, and their capacity to act as radiosensitizers was confirmed by clonogenic assays. The integrity of the NPs in vitro was also ascertained due to the potentially adverse effects of free gadolinium in the body. The activity of the NPs was then studied under hypoxia since this is often a barrier to effective radiotherapy. In vitro radiosensitization experiments were performed with both the hypoxia mimetics deferoxamine and cobalt chloride and also under true hypoxia (oxygen concentration of $0.2 \%$ ). It was shown that the radiosensitizing NPs were able to cause a significant increase in cell death even after irradiation under hypoxic conditions such as those found in tumors. Subsequently, the synthesized NPs were used to modify polystyrene embolization microparticles. The NPs were sintered to the surface of the microparticles by heating at $230^{\circ} \mathrm{C}$ for 15 minutes. This resulted in a good coverage of the surface and to generate embolization particles that were shown to be radiosensitizing. Such multimodal particles could therefore result in occlusion of the tumor blood vessels in conjunction with localized reactive oxygen species generation, even under hypoxic conditions such as those found in the center of tumors.

Keywords: cancer, ROS, reactive oxygen species, titania, multimodal

\section{Introduction}

One of the major limitations of radiotherapy is that both healthy tissues and cancerous tissues can be affected by the ionizing radiation. To overcome this, radiosensitizing materials can be introduced into tumors to increase the susceptibility of the cancerous cells to radiation. Radiation therapy may be used before surgery to help shrink tumors or afterward in order to destroy any remaining cancerous cells (National Cancer Institute).

We have previously demonstrated that rare earth doped titania nanoparticles (NPs) can be used to enhance the efficacy of radiotherapy both in vitro and in mouse xenograft models. ${ }^{1,2}$ In this study, we aimed to synthesize the NPs by a scalable route, to verify the integrity of the particles, and to further assess the efficacy of the NPs under the hypoxic conditions found in the majority of tumors. Furthermore, the utilization 
of the doped titania NPs as part of a composite embolization particle is described.

We have previously described the synthesis of radiosensitizing doped titania NPs by a sol-gel method. ${ }^{1}$ While effective, it is difficult to produce large-scale quantities of NPs for clinical use via this method. Herein, we therefore investigated the use of flame spray pyrolysis (FSP) to generate the NPs at scale. In addition to verifying the efficacy of the NPs generated by an alternative method, it was also important to show the integrity of the NPs with respect to the gadolinium dopant. Gadolinium chelates are often used to improve tissue contrast in magnetic resonance imaging (MRI); however, there are concerns about the safety of gadolinium-based contrast agents since they can adversely affect patients with renal dysfunction. This population of patients can develop nephrogenic systemic fibrosis leading to disabling contractures and even death or acute kidney injury at high doses. ${ }^{3}$ Free gadolinium may also act as a calcium channel blocker and interact with signaling involved in intracellular and extracellular adenosine triphosphate (ATP) hydrolysis. It is therefore crucial to assess uncomplexed gadolinium in formulations.

The efficacy of conventional radiotherapy relies upon an adequate supply of oxygen to the tumor cells; however, it is now well established that human solid tumors contain a substantial fraction of cells that are hypoxic. This chronic hypoxia that is seen in tumors is often referred to as diffusionlimited hypoxia since it arises from the large intervascular distance that is beyond the diffusion limit of oxygen (estimated to be between 75 and $200 \mu \mathrm{m}$ ). Additionally, transient "acute" perfusion-limited hypoxia may occur because of unstable blood flow in vessels, which results in periods of time when blood flow to a region is decreased or blocked. When tissue becomes hypoxic, several signaling pathways are activated, altering the behavior of the cells to enable them to adapt to oxygen deprivation. These include an increase in the capacity for anaerobic glycolysis for energy production and in vivo mediate changes in blood flow and stimulate angiogenesis. ${ }^{4}$ However, in the context of radiotherapy, the concentration of oxygen during or within milliseconds of irradiation is critical in determining DNA damage and subsequent biological response, with the biological effectiveness of a given dose significantly greater for well-oxygenated cells than for hypoxic cells. For X-ray oxygen enhancement ratio (OER) (which is defined as the ratio of doses under hypoxia compared to aerated conditions required to produce the same biological effect), values between 2.5 and 3.5 are typically reported for a range of biological end points, including clonogenic survival. Enhancement of the efficacy of radiotherapy using radiosensitizers that can act under hypoxic (and also normoxic) conditions would be a promising way to achieve improved therapeutic outcome. A number of radiosensitizers for hypoxic cells have been described in the literature. These are primarily the nitroimidazoles that are found to mimic the effect of oxygen in the radiochemical process. ${ }^{5,6}$ However, most clinical trials have failed to demonstrate significant efficacy using these sensitizers, mainly because of undesirable side effects such as neurotoxicity. ${ }^{7}$ We have previously described the activity of doped titania NPs to act as radiosensitizers under normoxic conditions. ${ }^{1}$ Since the generation of electrons from titania should not be dependent upon the presence of molecular oxygen, we sought to investigate whether the NPs still showed effective radiosensitization under hypoxic conditions.

The utility of the NPs was further enhanced by the preparation of a composite embolization particle. Embolization is a clinically relevant technique in which a blood vessel is deliberately occluded to prevent blood flow and produce ischemia within a tumor, resulting in tumor necrosis. To date, this technique is used in clinical practice for the treatment of hepatocellular carcinoma, hepatic metastases from colorectal and neuroendocrine tumors and renal carcinoma. Radiosensitizer embolic particles have previously been developed to combine an embolic agent with a radioactive element such as yttrium-90 to provide localized radiotherapy. However, there are several difficulties involved in using radioactive elements such as their storage, handling, use and disposal. A more useful approach would be to combine an embolic particle with a radiosensitizer that would be inert until activation by X-rays. We therefore designed a multimodal embolization particle by coating microparticles with the doped titania NPs. Furthermore, this could be combined with an imaging particle since we have previously shown that the polystyrene (PS) core can incorporate tantalum NPs for MRI to locate the particles in vivo without activation of the radiosensitizer. ${ }^{8}$

\section{Materials and methods}

\section{NP and embolization particle synthesis}

\section{FSP synthesis of doped titania NPs}

In a typical experiment, the appropriate amounts of titanium and gadolinium precursors for a $5 \mathrm{at} \% \mathrm{Gd}$ in $\mathrm{TiO}_{2}$ were added to a solvent and stirred for 1 hour. The solution was sprayed through the nozzle. The spray was defined by the speed of the precursor injection and the $\mathrm{O}_{2}$ dispersion gas rate and was ignited with a pilot flame made of methane and oxygen set at 1.5 and $3.2 \mathrm{~L} / \mathrm{min}$, respectively. The powder resulted from the combustion of the precursors and was collected 
under vacuum onto a glass fiber filter paper. Finally, the white powder was fired at $500^{\circ} \mathrm{C}$ for 2 hours. NPs including gadolinium are denoted by $\mathrm{TiO}_{2} @ \mathrm{x} \% \mathrm{Gd}$. Control samples were also prepared without the addition of rare earth. As a further control, samples were compared to titania NPs (P25) manufactured by Degussa (Evonik). This is a nanopowder with a $21 \mathrm{~nm}$ primary particle size.

\section{Silica coating of doped titania NPs}

Silica coating of the NPs was performed as described in Townley et al. ${ }^{1}$ Briefly, titania NPs (4.52 g) were resuspended in $200 \mathrm{~mL}$ Milli-Q water ( $\mathrm{pH} 4.5)$ (solution I). Next, 3-mercaptopropyltrimethoxy-silane (1.89 mL; SigmaAldrich) was added to $50 \mathrm{~mL}$ Milli-Q water (solution II). Twenty milliliters of solution II were then added to solution I and stirred. After 1 hour, sodium silicate $(40 \mathrm{~mL}$; SigmaAldrich) was added for 10 minutes. The zeta potential of the coated NPs was measured at pH 7 using a Zetasizer Nano (Malvern Instruments, Malvern, UK) and folded capillary cells (DTS1060; Malvern Instruments). NPs coated with silica are denoted by@Si.

\section{Microparticle coating with NPs}

PS microparticles were either synthesized in the laboratory or purchased from Duke Scientific as dry green fluorescent $40 \mu \mathrm{m}$ PS divinylbenzene beads (Product code: $35-7$ ). The laboratory synthesis of the PS microparticles was carried out by the suspension copolymerization of styrene and ethylene glycol dimethacrylate (EGDMA), as previously described by Ihara et al. ${ }^{9}$ An oil phase was created by mixing $2.5 \mathrm{~mL}$ of styrene (Sigma-Aldrich), $2.5 \mathrm{~mL}$ of EGDMA (SigmaAldrich) and $50 \mathrm{mg}$ of azobisisobutyronitrile (AIBN; SigmaAldrich). The oil phase was then added to $30 \mathrm{~mL}$ of aqueous $4 \mathrm{wt} \%$ poly(vinyl alcohol) (PVA) (87\%-90\% hydrolyzed, average molecular weight 30,000-70,000; Sigma-Aldrich) in a round-bottomed flask. The mixture was stirred at $250 \mathrm{rpm}$ for 1 hour at room temperature and then left to stand for 24 hours at $60^{\circ} \mathrm{C}$. The particles were collected by centrifugation, washed in $\mathrm{ddH}_{2} \mathrm{O}$ twice, resuspended in $30 \mathrm{~mL} \mathrm{ddH}_{2} \mathrm{O}$ and refluxed overnight to remove any remaining PVA. The particles were then collected by centrifugation, washed with methanol twice and dried under vacuum.

Both the laboratory-synthesized PS microparticles and the purchased PS divinylbenzene microparticles were coated with the gadolinium-doped titania NPs. The microparticles were mixed with the NPs in a 1:9 ratio $(\mathrm{v} / \mathrm{v})$. The titania NPs were then sintered onto the surface of the PS microparticles by heating the mixture to $230^{\circ} \mathrm{C}$ (which is above the glass transition temperature of the PS microspheres - data not shown). The reaction was performed in a Carbolite RWF 1200 furnace at a ramping rate of $7 \% \mathrm{~min}$. The mixture was held at $230^{\circ} \mathrm{C}$ for 15 minutes to limit any potential change in crystal phase of the doped titania NPs. The doped titania NP-coated microparticles were separated from the excess NPs using a sucrose density gradient containing 60\% and $15 \%$ sucrose and centrifugation for 1 hour at 9,000 rpm. The band containing the coated microparticles was extracted, centrifuged and washed in $\mathrm{ddH}_{2} \mathrm{O}$ three times to remove the sucrose. Finally, the prepared NP-coated polystyrene particles (PS-NP) were dried overnight under vacuum.

\section{Particle characterization techniques}

\section{Transmission electron microscopy (TEM)}

TEM was used to assess the size, morphology and crystal structure of the gadolinium-doped titania NPs. TEM was performed using a JEOL JEM-2010 microscope equipped with $\mathrm{a} \mathrm{LaB}_{6}$ thermionic electron gun operating at a primary beam energy of $200 \mathrm{keV}$ and an Oxford Instruments INCA X-ray analysis system for carrying out energy-dispersive X-ray spectroscopy (EDX). By analyzing the characteristic $\mathrm{X}$-rays produced by the interaction of the primary electron beam with the sample, the elements present in the sample could be determined. TEM specimens were prepared by resuspending the NPs in ethanol and drop casting onto holey carbon-coated grids (Agar Scientific).

The crystal structure of the TiOx NPs was obtained by X-ray diffraction (XRD) using a fully automated Siemens D5000 powder diffractometer employing copper Ka radiation $(\mathrm{k}=0.15406 \mathrm{~nm})$ and a secondary monochromator. The sample was supported on a single crystal of silicon and continuously spun during data collection. The sample was scanned using a step size of $0.05^{\circ}$, between the range of $10^{\circ}-90^{\circ} 2 \theta$, and a count time of 12 seconds per step. The crystal phases were determined by comparing the diffraction pattern obtained with standard data from the International Centre of Diffraction Data.

\section{Scanning electron microscopy (SEM)}

SEM was used to evaluate the size distribution and surface coverage of the NP-coated microspheres. SEM was performed using a JEOL JSM-840F microscope operating at a primary beam energy of $3 \mathrm{keV}$, and images were collected in secondary electron imaging mode. SEM specimens were prepared by dusting onto a carbon-taped SEM stub (Agar Scientific) and then coated with a $3 \mathrm{~nm}$ layer of platinum to reduce charging during operation. 


\section{Arsenazo III assay}

Titania NPs doped with 5\% gadolinium prepared by FSP were coated with silica ( $\mathrm{TiO}_{2} @ 5 \% \mathrm{Gd}(\mathrm{FSP}) @ \mathrm{Si}$ ) and analyzed for gadolinium leaching. The sample was resuspended in Milli-Q water, sonicated and filtered. The sample was diluted (1:401), and three UV-vis spectra were collected for the sample. Absorbance values at $300 \mathrm{~nm}$ were determined. Based on a calibration curve for control titania NPs (P25; Degussa), the initial concentration of the sample after filtration was calculated $(5.45 \mathrm{mg} / \mathrm{mL})$. A total of $500 \mu \mathrm{L}$ of the sample was injected into Slide-A-Lyzer Dialysis Cassette (ThermoScientific) and dialyzed against Milli-Q water $(55 \mathrm{~mL})$ with constant stirring at room temperature. Gadolinium (III) nitrate hexahydrate was used as a source of free gadolinium in a positive control experiment. A total of $500 \mu \mathrm{L}$ of the gadolinium (III) chloride hexahydrate $(0.788 \mathrm{mg} / \mathrm{mL})$ was injected into Slide-A-Lyzer Dialysis Cassette (ThermoScientific) and dialyzed against water $(55 \mathrm{~mL})$ with constant stirring at room temperature. Additionally, $500 \mu \mathrm{L}$ of uncoated $\mathrm{TiO}_{2} @ 5 \% \mathrm{Gd}$ (FSP) $(5.45 \mathrm{mg} / \mathrm{mL})$ sample was injected into Slide-A-Lyzer Dialysis Cassette (ThermoScientific) and dialyzed against water $(55 \mathrm{~mL})$ with constant stirring at room temperature.

The water ("sink") was assessed for free gadolinium after 1 day of dialysis and up to 14 days. Samples for measurement were prepared by mixing $100 \mu \mathrm{L}$ of $0.2 \mathrm{mM}$ Arsenazo III and $900 \mu \mathrm{L}$ of sink. Blanks were prepared by mixing $100 \mu \mathrm{L}$ of $0.2 \mathrm{mM}$ Arsenazo III and $900 \mu \mathrm{L}$ of Milli-Q water. Absorbance measurements were then taken at $652 \mathrm{~nm}$. All sink samples were collected for further analysis by inductively coupled plasma mass spectrometry (ICP-MS).

\section{Cell assays}

\section{Cell culture}

The effectiveness of the NPs and the NP-coated microparticles was determined in vitro on immortalized cancer cell lines obtained from the American Type Culture Collection (ATCC, Manassas, VA, USA): rhabdomyosarcoma lines, RD (ATCC code CCL-136) and RH30 (ATCC code CRL-7763), and the cervical cancer HeLa line (ATCC code CCL-2). Cells were grown in growth medium (Dulbecco's Modified Eagle's Medium [DMEM]; Sigma-Aldrich) supplemented with 10\% fetal calf serum (Sigma-Aldrich), 2 mM L-glutamine (SigmaAldrich), $100 \mathrm{U} / \mathrm{mL}$ penicillin (Sigma-Aldrich) and $0.1 \mathrm{mg} / \mathrm{mL}$ streptomycin (Sigma-Aldrich) and incubated at $37^{\circ} \mathrm{C}$ in a $5 \% \mathrm{CO}_{2}$ atmosphere. Cells were passaged every $3-4$ days.

\section{Clonogenic assay}

Flasks of HeLa cells were seeded and cells incubated for 4 hours to allow attachment. NPs were added to the appropriate flasks and incubated overnight prior to irradiation. Following irradiation, cells were incubated for 1 hour at $37^{\circ} \mathrm{C}$. Cells were then trypsinized, counted and petri dishes seeded with $1,000 \mathrm{cells} / \mathrm{dish}$. At least three petri dishes were seeded for each experimental condition. The cells were incubated at $37^{\circ} \mathrm{C}$ in a $5 \% \mathrm{CO}_{2}$ atmosphere undisturbed for 2 weeks. Cells were then stained by washing twice with phosphate-buffered saline (PBS), fixed using 1\% (v/v) glutaraldehyde (aq) for 30 minutes prior to adding $0.5 \%(\mathrm{w} / \mathrm{v})$ crystal violet stain (aq) for at least 1 hour and surviving colonies subsequently counted ( $>50$ cells). The surviving fraction was then calculated by dividing the colonies counted by the number of cells seeded and correcting for the plating efficiency determined using the 0 Gy control.

\section{Cell proliferation after incubation with radiosensitizing embolization microparticles}

RD cells were seeded on two separate 96-well plates at $1 \times 10^{4}$ cells/well in $150 \mu \mathrm{L}$ of fresh media and incubated overnight to allow the cells to adhere to the plate. The following day duplicate plates were treated with 1) $1.5 \mathrm{mg}$ of undoped titania NPs, 2) $1.5 \mathrm{mg}$ of gadolinium-doped titania NPs, 3) $15 \mathrm{mg}$ of microspheres coated with undoped titania NPs, 4) $15 \mathrm{mg}$ of microspheres coated with gadoliniumdoped titania NPs or 5) PBS as a control. The next day one plate of particle-treated cells was exposed to $3 \mathrm{~Gy}$ of X-rays, while the other plate was kept unirradiated as a control. After a further 24 hours, cell proliferation was determined by manual cell counting using a hemocytometer following the removal of the adherent cells using trypsinethylenediaminetetraacetic acid (EDTA).

\section{Hypoxia}

Incubation with hypoxia mimetics

In order to select the experimental concentrations of $\mathrm{CoCl}_{2}$ and deferoxamine, 48-hour concentration-response studies were conducted. RD cells were plated at a density of $1.5 \times 10^{4}$ cells/well (96-well plate) in $200 \mu \mathrm{L}$ of growth medium, and cells were allowed to attach for 24 hours prior to treating with various concentrations of the compounds.

$\mathrm{CoCl}_{2}$ stock solution was dissolved directly in DMEM medium and filter-sterilized $(0.2 \mu \mathrm{m}$ filter $) .{ }^{10}$ Deferoxamine stock solution ( $25 \mathrm{mM}$ ) was dissolved in Milli-Q water, and then the stock solution was filter-sterilized $(0.2 \mu \mathrm{m}$ cellulose acetate). Each variation was performed in at least triplicate. Cells were subsequently rinsed with PBS to remove nonadherent cells, followed by collection of the remaining attached cells using trypsin-EDTA, and manually counted to assess proliferation. 
The concentration of all tested samples was $450 \mathrm{nmol}$ (in $0.2 \mathrm{~mL}$ medium). All samples were irradiated at 0 and $5 \mathrm{~Gy}$ and allowed to recover in the incubator overnight. Next day, cells were rinsed with PBS to remove non-adherent cells, and the remaining cells were manually counted after detaching using trypsin-EDTA to assess proliferation.

\section{Experimental setup for irradiation under hypoxia}

Hypoxia experiments to assess cell proliferation were performed using an oxygen concentration of $0.2 \%$ in nitrogen and $5 \%$ carbon dioxide. Two hours prior to irradiation, cells were moved to a hypoxia chamber, which was flushed with gas of the abovementioned composition positioned on a $1 \mathrm{~mm}$-thick stainless steel shelf above the X-ray set. In the chamber, the cells were kept at $37^{\circ} \mathrm{C}$ by placing the flasks on top of a $5 \mathrm{~mm}$-thick aluminum plate heated by circulating warm water outside of the plate. Following irradiation, the cells were transferred to an incubator where hypoxia was maintained. The number of live cells was evaluated by manual cell counting after a further 24 hours.

\section{Irradiations}

X-ray exposures were performed with $250 \mathrm{kV}$ (constant potential) X-rays with $0.25 \mathrm{~mm}$-thick copper filter (half-value layer of $1.08 \mathrm{~mm} \mathrm{Cu}$ ) at a dose rate of $0.57 \mathrm{~Gy} / \mathrm{min}$ measured using calibrated EBT3 gafchromic film (International Speciality Products, Wayne, NJ, USA). All doses quoted in this article refer to dose to water, with samples with and without NPs exposed for the same amount of time.

\section{Results \\ Doped titania NPs \\ FSP synthesis route}

We have previously shown that doped titania NPs can be prepared by a sol-gel process. ${ }^{1}$ An alternative FSP method was used here that would be more suitable for large-scale production of the NPs for clinical applications. FSP synthesis is a promising technique for fast and scalable synthesis of NPs. Precursors are dissolved/dispersed in a highly exothermic solvent and combusted in a flame. It is commonly used in industry as large quantities of product can be prepared with no aqueous by-product. ${ }^{11}$ The mechanism of particle formation is based on a gas-to-matter principle and can be divided into four main steps: 1) precursor spray evaporation/ decomposition forming metal vapor, 2) nucleation as a result of supersaturation, 3) growth by coalescence and sintering and 4) particle aggregation/agglomeration.

A series of gadolinium-doped titania NPs were prepared by this method, and the results presented here are for the $5 \mathrm{at} \%$ gadolinium-doped sample. TEM, EDX and XRD analyses were carried out on the synthesized NPs (Figure 1). The TEM images show the NPs to be of spherical nature, with a particle size of 5-20 nm (Figure 1A and B). XRD analysis revealed the presence of both the anatase and the rutile phases with a crystallite size around 6-8 $\mathrm{nm}$ for anatase and $10-12 \mathrm{~nm}$ for rutile (Figure 1D). No additional crystalline phase other than rutile and anatase is discernible although other Gd phases may still be present (diffractometer resolution may be too low to detect any peaks at such small concentrations). Furthermore, no significant shift in the anatase or rutile peaks was detected, as one would expect when considering the cation sizes in a sixfold coordination of the rare earth $\left(\mathrm{rGd}^{3+}=0.938 \AA\right.$ compared to $\mathrm{rTi} i^{4+}$ $=0.605 \AA$ ). It was found that furnace calcination in air at $500^{\circ} \mathrm{C}$ aiming to remove any carbon residue did not change the particle size and rutile/anatase ratio. According to high angle annular dark field images (data not shown), Gd is present at the surface of the NPs, although the resolution is limited. The XPS spectrum of the 5 at $\%$ doped sample concurs with this supposition as it shows the presence of Gd. ICP-MS results showed that the Gd content of the FSP-produced materials correlated well with NPs with theoretical Gd content of $10.4 \mathrm{wt} \% \mathrm{Gd}$ and $48.4 \mathrm{wt} \%$ Ti. Before silica coating, the NPs were shown to have a zeta potential of $-13.65 \pm 3.7 \mathrm{mV}$ and after coating $-44.0 \pm 0.3 \mathrm{mV}$. This is consistent with our previous data. ${ }^{1}$

\section{Integrity of NPs}

Since free gadolinium has the potential to be toxic in patients, we tested whether any free gadolinium was released from the surface of the NPs. The method was taken from McNeil. ${ }^{12}$ Briefly, NPs were incubated in water for a period of 14 days, and the sink solution assessed for free gadolinium at 1, 5, 6, 8 and 14 days. Gadolinium (III) nitrate hexahydrate was used as a positive control in the assay due to its solubility. Using the arsenazo assay, no gadolinium was detected from the sink solution collected from samples containing the NPs.

Due to the limits of detection of the arsenazo assay, the same sink samples were also analyzed by ICP-MS (data not shown). Here, the detection limit is $<0.01 \mathrm{ppm}$, but again no gadolinium was detected, indicating that the NP structures are not changed by incubation in aqueous solution and that the NPs maintain their integrity.

\section{Radiosensitizing properties of the NPs}

The ability of the NPs to act as radiosensitizers was verified using the clonogenic assay. The HeLa cell line was used since our experimental RD and RH30 cell lines do not form colonies well. The variation in surviving fraction (determined from colonies counted and corrected for the plating efficiency, 
A

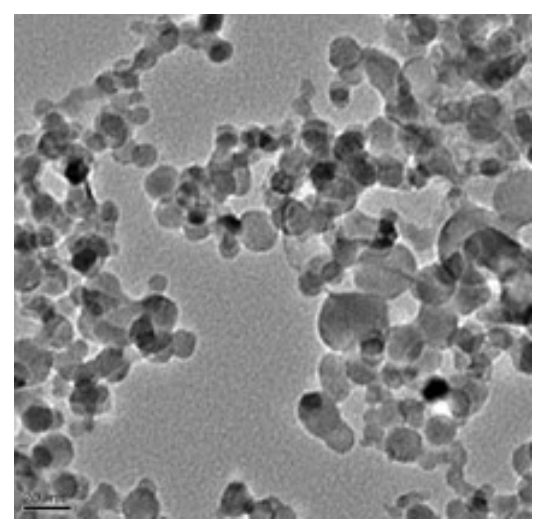

C

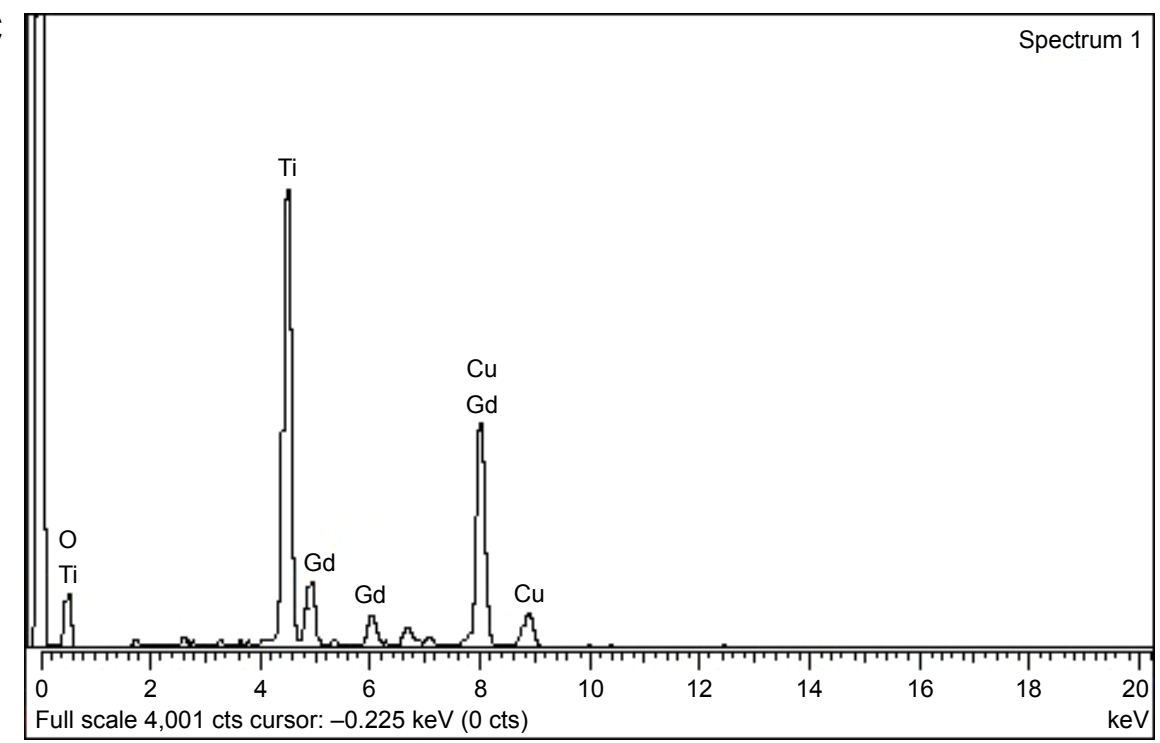

B

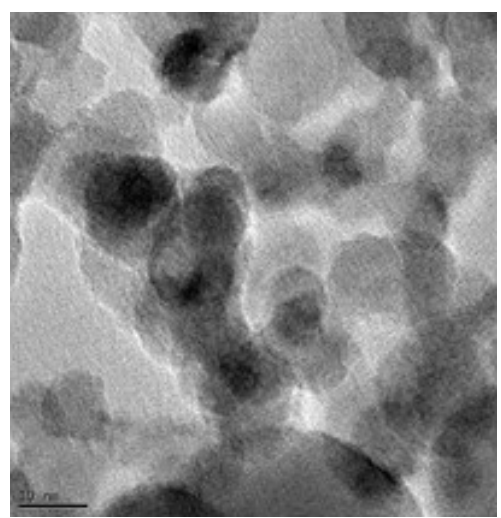

Spectrum 1

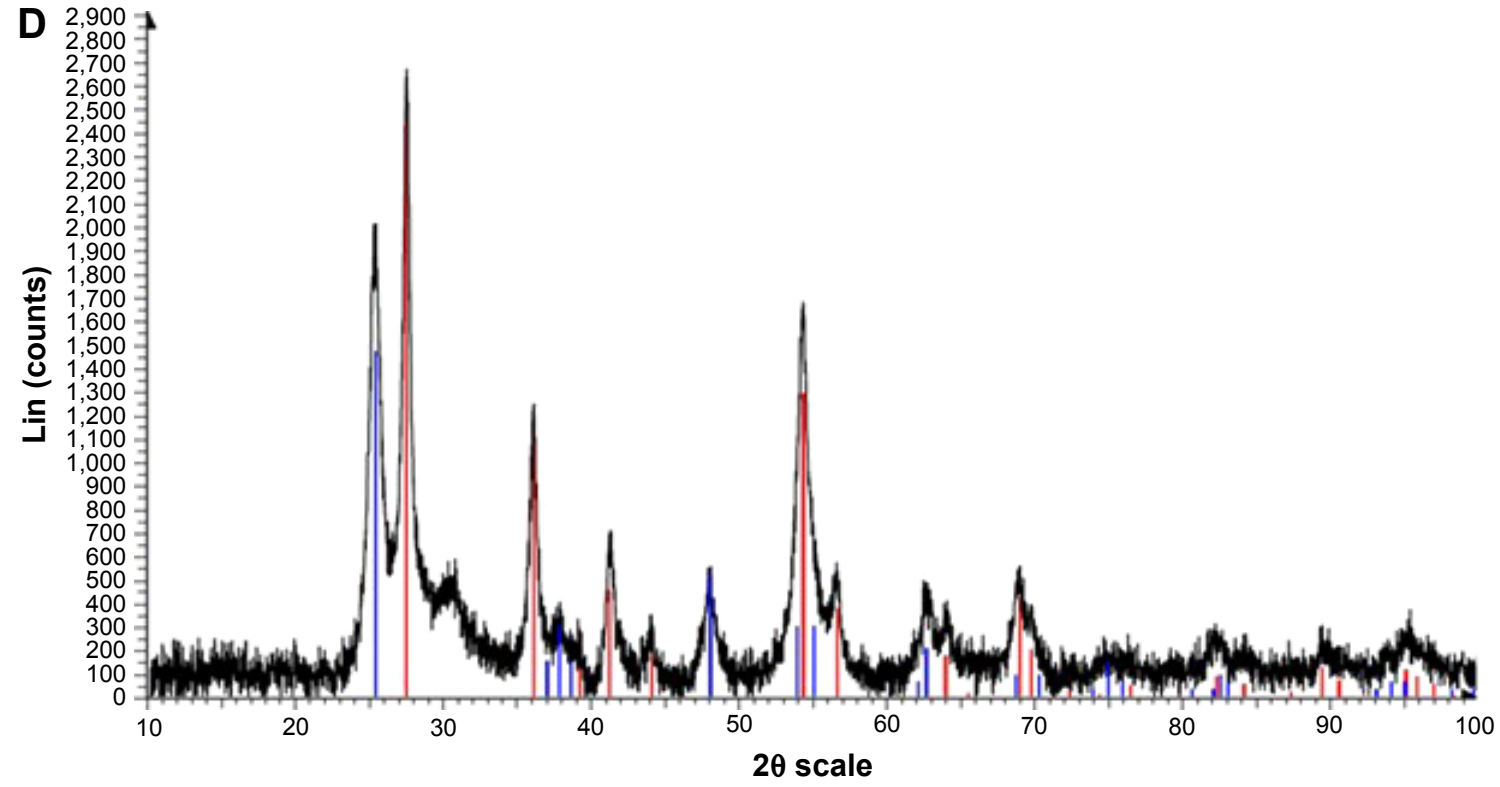

Figure I Material properties of $\mathrm{TiO}_{2} @ G d$ NPs showing size, shape and crystallinity.

Notes: Doped titania NPs were synthesized using FSP. (A) TEM image showing the size and shape of the NPs, Scale bar shown is 20 nm. (B) higher resolution image illustrating the crystallinity of the titania sample, Scale bar shown is $10 \mathrm{~nm}$. (C) EDX confirming the presence of gadolinium in the doped titania NPs and (D) diffraction pattern (black line) showing peak positions from the literature: anatase, $\mathrm{TiO}_{2}$ (PDF: 00-02I-1272), in blue and rutile, TiO (PDF: 04-003-0648), in red.

Abbreviations: NPs, nanoparticles; FSP, frame spray pyrolysis; TEM, transmission electron microscopy; EDX, energy-dispersive X-ray spectroscopy; PDF, powder diffraction file. 
$P E)$ as a function of dose and NP treatment is shown in Figure 2. In the absence of irradiation, there was no significant difference between the controls $\left(P E_{\text {con }}=0.88 \pm 0.10\right)$ and either the undoped $\left(P E_{\text {undoped }}=0.72 \pm 0.04\right)$ or the doped titania $\left(P E_{\text {doped }}=0.90 \pm 0.009\right)$. After irradiation with $3 \mathrm{~Gy}$, there was no significant difference between the number of colonies seen in the sample with no NPs and those incubated with titania NPs. However, it can be seen that there was a highly significant $(P \leq 0.05)$ difference between samples incubated with no NPs compared to those incubated with doped titania NPs. This confirms that doped titania NPs prepared by FSP are capable of radiosensitizing in a similar fashion to particles that we had previously prepared by sol-gel ${ }^{1}$ and therefore provides a methodology for the large-scale production of these NPs for radiobiological testing and clinical use.

\section{Radiosensitizing under hypoxic conditions}

To further investigate the ability of the particles to act as radiosensitizers under clinically relevant conditions, NPs were introduced into cells either under hypoxia-mimetic conditions (using $\mathrm{CoCl}_{2}$ or desferrioxamine [DFO]) or under true hypoxia with the cells incubated and irradiated under reduced oxygen conditions.

\section{Cobalt chloride}

Cell proliferation in the absence of $\mathrm{CoCl}_{2}$

Figure 3 shows that there was no significant variation in cell numbers between unirradiated samples (with and without NPs, incubated in the absence of $\mathrm{CoCl}_{2}$ ), confirming that

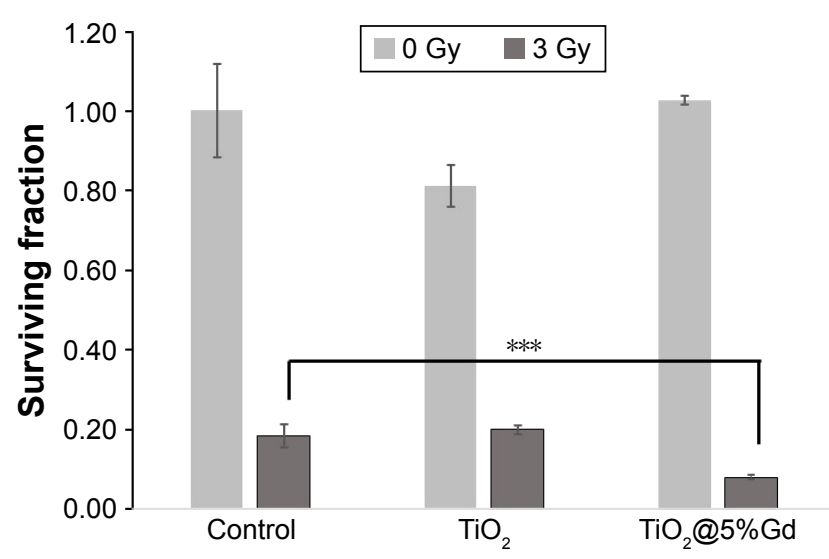

Figure 2 Effect of doped titania NPs on the clonogenic survival of HeLa cells following $3 \mathrm{~Gy}$ irradiation.

Notes: HeLa cells were incubated with titania $\mathrm{NPs}\left(\mathrm{TiO}_{2}\right)$, titania NPs doped with $5 \%$ gadolinium $\left(\mathrm{TiO}_{2}+5 \% \mathrm{Gd}\right.$ ) or no NPs (control), overnight, prior to $3 \mathrm{~Gy}$ irradiation. Data are shown as the surviving fraction for each treatment and are corrected for plating efficiency. Data are shown as mean \pm standard deviation $(n=3)$. Significance was tested using a two-tailed $t$-test $(* * * P \leq 0.005)$.

Abbreviation: NPs, nanoparticles. the NPs are inactive in the absence of irradiation and are biocompatible. After irradiation at $5 \mathrm{~Gy}$, there is a small decrease in cell number in the presence of P25@Si or TiO $@$ $\mathrm{Si}$ in both RD and RH30 cell lines. In the presence of the TiO $@$ Gd@Si radiosensitizer, there is a significant decrease in cell number, resulting in a cell survival rate of $54 \%$ for RH30 and 38\% for RD cells (which is in line with the clonogenic survival data seen with HeLa cells in Figure 2).

\section{Determination of experimental $\mathrm{CoCl}_{2}$ concentration}

The variation of cell proliferation (determined by cell count measurements) was determined for RH30 and RD cells as a function of $\mathrm{CoCl}_{2}$ concentration over a range from $0 \mathrm{nM}$ to $800 \mu \mathrm{M}$. The number of live cells was evaluated by manual cell counting after incubation with the compound for 24 hours. No reduction in cell count was observed for either RD or RH30 cells up to $150 \mu \mathrm{M}$ (data not shown), and this concentration was used for further experimentation.

\section{Cell proliferation in the presence of $\mathrm{CoCl}_{2}$}

When the experiment was performed in $\mathrm{RH} 30$ cells in the presence of $\mathrm{CoCl}_{2}$, no differences were seen in the results compared to the corresponding results in the absence of $\mathrm{CoCl}_{2}$ (Figure 3 ). While unirradiated $\mathrm{RD}$ cells showed no change in cell number when incubated in the presence of $\mathrm{CoCl}_{2}$, a decrease in cell number was seen in irradiated samples in the presence of $\mathrm{CoCl}_{2}$ for $\mathrm{P} 25 @ \mathrm{Si}$ or $\mathrm{TiO}_{2} @ \mathrm{Si}$ compared to the corresponding data for cells irradiated in the absence of $\mathrm{CoCl}_{2}$; however, the presence or absence of $\mathrm{CoCl}_{2}$ made no difference to the observed response for irradiated cells containing the $\mathrm{TiO}_{2} @ \mathrm{Gd} @ \mathrm{Si}$ radiosensitizer NPs. The unexpected increase in cell death in $\mathrm{RD}$ cells in the presence of $\mathrm{CoCl}_{2}$ may be due to an additive effect between the irradiation and $\mathrm{CoCl}_{2}$ treatment, in which small amounts of reactive oxygen species (ROS) generated by the undoped titania NPs result in greater cell kill due to the compromised enzymatic repair systems. In the case of $\mathrm{TiO}_{2} @$ Gd@Si, it may be that no further increase in cell kill can be attained since a threshold for the maximal amount of ROS that can be upregulated by the cell has already been reached.

\section{DFO}

The iron chelator DFO is a second commonly used hypoxiamimetic agent and was further used to investigate the efficacy of the NPs under simulated hypoxia. RH30 and RD cells were also incubated with DFO over a range from $0 \mathrm{nM}$ to $500 \mu \mathrm{M}$ to determine the concentration at which significant reduction in cell number is seen. RD cells showed no change 

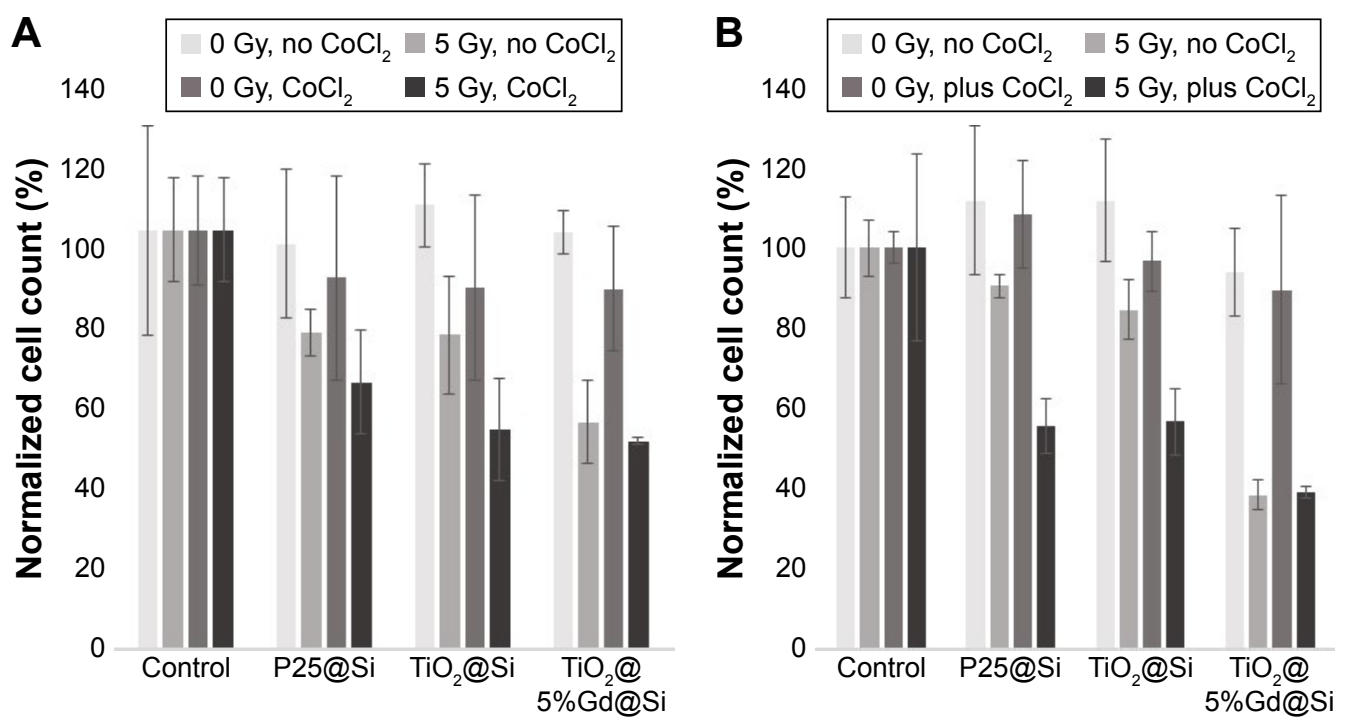

Figure 3 Effect of the hypoxia-mimetic agent $\mathrm{CoCl}_{2}$ on cell proliferation in the presence of titania NPs.

Notes: Rhabdomyosarcoma cells (A) RH30 and (B) RD were incubated with commercial P25 titania NPs, FSP-synthesized titania NPs, FSP-synthesized titania NPs doped with $5 \%$ gadolinium or no NPs, overnight. Samples were subsequently incubated either in the presence or in the absence of I50 $\mu \mathrm{M}$ CoCl ${ }_{2}$ and then exposed to either 0 or $5 \mathrm{~Gy}$ irradiation. The number of live cells was evaluated by manual cell counting after a further 24 hours. All data are normalized to the cell-only control under each condition that is set to $100 \%$. The data are shown as mean \pm standard deviation $(n=3)$

Abbreviations: NPs, nanoparticles; FSP, frame spray pyrolysis.

in cell number up to $1 \mu \mathrm{M}$, and so this was used for further experimentation. RH30 cells were more sensitive to the compound, and so a concentration of $0.1 \mu \mathrm{M}$ was used (data not shown). The presence of DFO does result in a slight increase in cell number compared to the control, although it is not statistically significant (Figure 4). In the presence of the three types of NPs, there is no significant difference from the control either in the unirradiated or in the irradiated cells (Figure 4). Data shown in Figures 2 and 3, and also obtained previously, ${ }^{1,2}$ show that the radiosensitizer $\mathrm{TiO}_{2} @ \mathrm{Gd} @ \mathrm{Si}$ NPs increase cell death after irradiation; however, the presence of DFO prevented the expected decrease.

\section{Hypoxia}

While the hypoxia-mimetic agents can activate similar signaling pathway in cells similar to those observed as a result of hypoxia, it does not prevent the oxygen present in the cell from directly modifying the radiation-induced DNA damage, which is believed to be the dominant mechanism for the oxygen effect. It was therefore also important to investigate the action of the particles in cells cultured under reduced oxygen conditions. The experimental proliferation data for RH30 cells cultured in the absence of NPs performed under hypoxic conditions showed no significant difference in cell number following an exposure of 5 Gy compared to
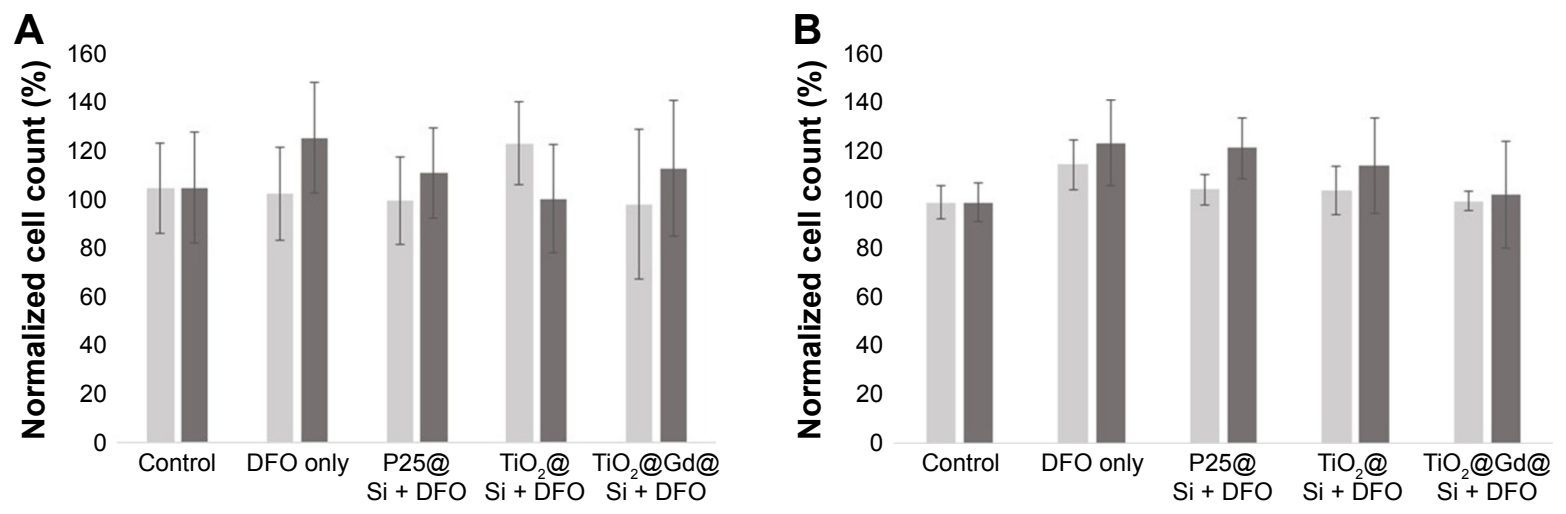

Figure 4 Effect of the hypoxia-mimetic agent DFO on cell proliferation in the presence of titania NPs.

Notes: Rhabdomyosarcoma cells (A) RH30 and (B) RD were incubated with commercial P25 titania NPs, FSP-synthesized titania NPs, FSP-synthesized titania NPs doped with $5 \%$ gadolinium or no NPs, overnight. Samples were also incubated either in the presence or in the absence of DFO, (A) $0.1 \mathrm{mM}$ and (B) I $\mu$ M, and then exposed to either 0 (light gray bars) or $5 \mathrm{~Gy}$ (dark gray bars) irradiation. The number of live cells was evaluated by manual cell counting after a further 24 hours and normalized to show the cell-only control, in the absence of irradiation, as 100\%. Data are shown as mean \pm standard deviation $(n=3)$.

Abbreviations: DFO, desferrioxamine; NPs, nanoparticles; FSP, frame spray pyrolysis. 
an unirradiated control (Figure 5). Similarly, cell counts were also observed when the cells were incubated with the standard control (P25@Si) and TiO @ Si NPs prepared by FSP when exposed to either 5 Gy irradiation or unirradiated. Conversely, while cells incubated with the TiO $@ @ G d @ S i$ radiosensitizer NPs show no difference in the absence of radiation (as expected), after irradiation, a significant decrease of $29 \%(P=0.007, \leq 0.01)$ in the cell count was observed.

\section{Incorporation of TiO2:Gd NPs into embolization microparticles NP coating of PS microparticles}

PS microparticles were either prepared in the laboratory or commercial standards used in a range of sizes. The size of the embolization particles was varied since there will be a range in the diameter of the vessels supplying blood to the tumor. ${ }^{13}$

The bland embolization particles (Figure 6A) were coated with either control titania NPs or doped titania NPs. A number of methods were investigated, but the most successful was found to be sintering the titania NPs onto the PS, as shown in Scheme 1. The coating of the microparticles with NPs was assessed by SEM (Figure 6B).

\section{Radiosensitizing properties of embolization particles}

Radiosensitization of titania-coated embolization particles was tested in cell culture using a proliferation assay. It can be seen that in the unirradiated control samples, neither titania NPs alone nor PS microparticles coated with titania NPs were able to significantly affect cell count (Figure 7). Equally,

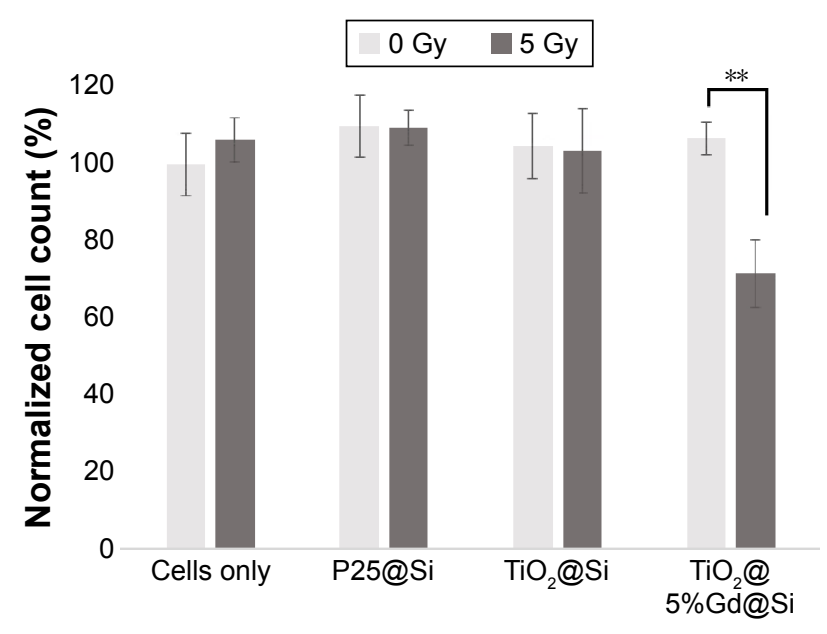

Figure 5 Effect of incubation under hypoxic conditions $\left(0.2 \% \mathrm{O}_{2}\right)$ on cell proliferation in the presence of titania NPs.

Notes: Rhabdomyosarcoma RH30 cells were incubated with commercial P25 titania NPs, FSP-synthesized titania NPs, FSP-synthesized titania NPs doped with $5 \%$ gadolinium or no NPs, overnight. The number of live cells was evaluated by manual cell counting after a further 24 hours. All data are normalized to the unirradiated cell-only control that is set to $100 \%$. Data are shown as mean \pm standard deviation $(n=3)$. Significance was tested using a two-tailed $t$-test $(* * P<0.0 \mathrm{I})$.

Abbreviations: NPs, nanoparticles; FSP, frame spray pyrolysis. the gadolinium-doped titania NPs did not significantly affect cell number in the unirradiated controls. Conversely, it was confirmed that both the gadolinium-doped NPs and the microparticles coated with the gadolinium-doped titania NPs were able to produce a significant reduction in cell number following irradiation (compared to undoped NPs where no significant difference was observed). Therefore, embolization microparticles coated with gadolinium-doped titania NPs would be expected to act as radiosensitizers in addition to acting as a physical block of nutrients and oxygen to the tumor.

\section{Discussion \\ NP synthesis and characterization}

Herein, we have described a scalable method for the production of radiosensitizing doped titania NPs, demonstrated the integrity of the NPs, investigated their efficacy under hypoxic conditions and shown further utility as a component of embolization microparticles.

We have previously shown the efficacy of doped titania NPs produced by a sol-gel batch method. To translate this technology to the clinic, a crucial step is to find a suitable, scalable, high-throughput method. Here, we have described the use of FSP to generate the NPs. The powders have 15-100 nm average particle sizes (APS) with specific surface areas of $30-100 \mathrm{~m}^{2} / \mathrm{g}$. The FSP technology can be used to produce mixed and single metal oxides easily from low-cost starting materials in a single step. Uniform particle size distributions are obtained as it is a vapor phase process. Metal carboxylates or alkoxides are often used as precursors, and thus, limited metal impurities or other unwanted contaminations such as halides would be found in the end product. Finally, the process has been shown to be scalable and products are already available commercially (Nanocerox). ${ }^{14}$

The NPs synthesized here were shown to be between 7.9 and $11.7 \mathrm{~nm}$ in diameter (Table 1) with anatase particles being smaller than rutile particles, and the presence of the gadolinium dopant was confirmed by EDX (Figure 1C). The gadolinium-doped NPs prepared by FSP were subsequently confirmed to act as radiosensitizers in cell culture, showing a large reduction in both clonogenic survival (Figure 2) and cell proliferation (Figure 3). Further tests were undertaken to ensure that there was no breakdown of the structure and consequent release of the rare earth component. This was important since gadolinium in its unbound state is extremely toxic and is a potent inhibitor of calcium channels and has significant cardiovascular and neurological toxicity. Gadolinium is known to accumulate in the liver, bone and 

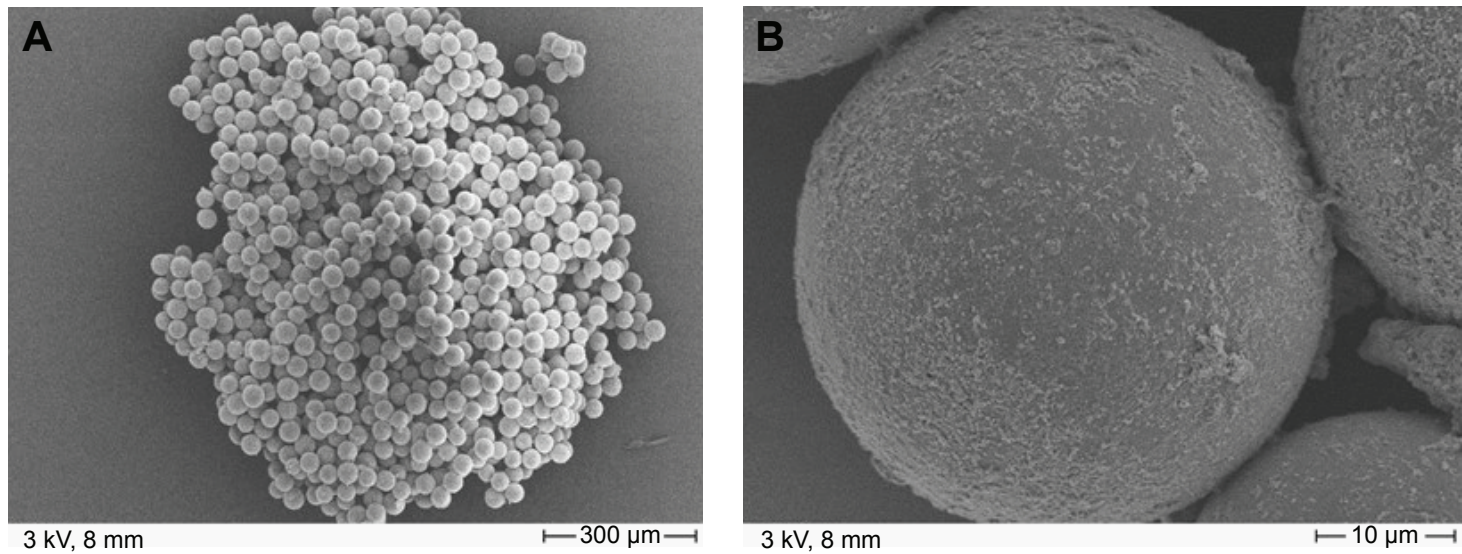

Figure 6 SEM images of PS embolization particles.

Notes: (A) Low-magnification and (B) high-magnification images of commercial fluorescent $39 \mu \mathrm{m}$ PS microparticles that have been coated with doped titania NPs. Abbreviations: SEM, scanning electron microscopy; PS, polystyrene; NPs, nanoparticles.

lymph nodes; ${ }^{15}$ and in mice, the median lethal dose $\left(\mathrm{LD}_{50}\right)$ of $\mathrm{GdCl}_{3}$ is only $100-200 \mathrm{mg} / \mathrm{kg} .{ }^{16}$ However, gadolinium in its chelated form is commonly used to improve tissue contrast in MRI and has been proven to be safe in patients with normal kidney function. Our data showed that there was no release of gadolinium from the NPs using either the arsenazo assay recommended by the National Characterization Laboratory (USA) or the ICP-MS. ${ }^{17}$ Additional investigations by protoninduced X-ray emission confirm that the structural integrity of the NPs has shown further evidence that there is no release of rare earth elements. ${ }^{18}$

\section{Efficacy of NPs under hypoxia}

While the NPs have been demonstrated to act as radiosensitizers under normoxic conditions, tumor cells are often hypoxic or anoxic. Hypoxia is one of the most important parameters that cause enhanced tumor aggressiveness and treatment resistance. This is because molecular oxygen is a potent radiosensitizer. However, this radiosensitization does not result from metabolic or physiological effects of the oxygen but reflects the fact that oxygen is an extremely electronaffinic molecule that is involved in the chemical reaction that leads to the production of DNA damage after the absorption of energy from ionizing radiation. ${ }^{19}$ Oxygen deprivation can therefore result in a significant reduction in the efficiency of radiation therapy. As such, it would be pertinent to assess the efficacy of the NPs under reduced oxygen conditions. Experiments were initially conducted with the hypoxia mimetics $\mathrm{CoCl}_{2}$ and DFO using concentrations shown to have no significant effect on cell proliferation. These compounds are commonly used as mimetics, because like hypoxia, they block the degradation, and thus induce the accumulation, of HIF $1 \alpha .{ }^{20}$ The transition metal, cobalt, has been shown to induce apoptosis via mitochondrial-mediated caspase 3 activation at concentrations $>50 \mu \mathrm{M}$ in the leukemic cell lines NB4 and U937. However, we found that samples containing control (undoped) NPs showed a decrease in cell number in the presence of $\mathrm{CoCl}_{2}$ after irradiation (compared to the same samples without $\mathrm{CoCl}_{2}$ ), although this was only statistically significant in RD cells. A study by Gault et $\mathrm{al}^{21}$ showed that there can be additive effects on DNA damage induction between $\mathrm{Co}$ (II) and irradiation. It was suggested that the toxicity of $\mathrm{Co}(\mathrm{II})$ and the toxicity of irradiation both arise from the production of ROS. Furthermore, Co(II)
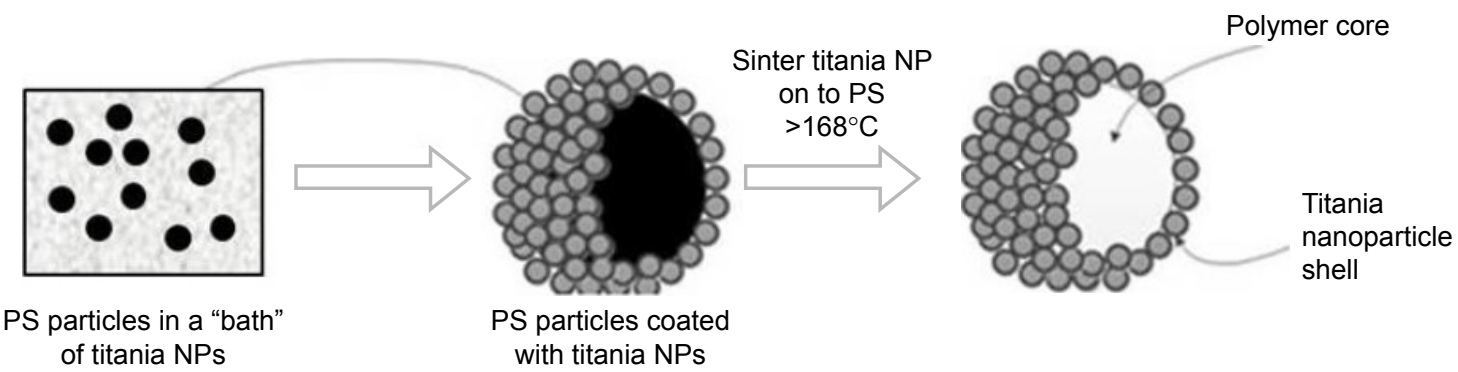

Scheme I Polymer microparticles were coated with doped titania NPs by a sintering method. Abbreviations: PS, polystyrene; NPs, nanoparticles. 


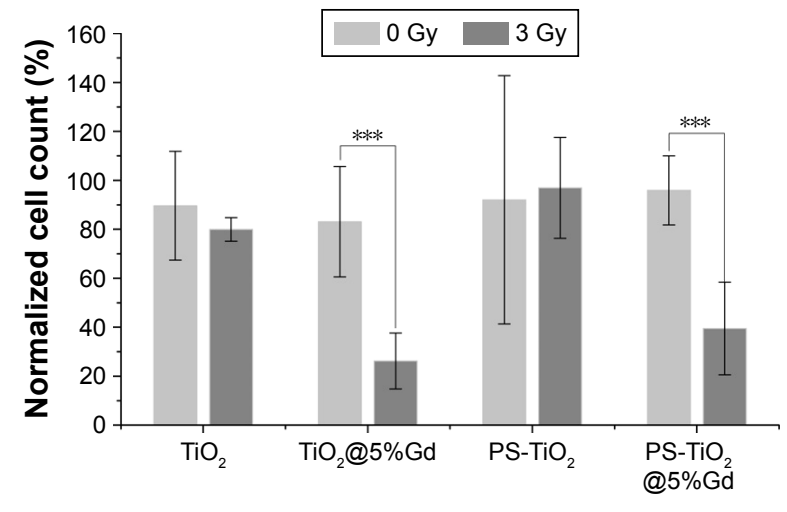

Figure 7 Doped titania NPs are still efficient radiosensitizers after coating embolic particles.

Notes: Rhabdomyosarcoma RD cells were incubated with a combination of particles and $X$-ray radiation ( 0 and $3 \mathrm{~Gy}$ dose). RD cells were incubated with either $15 \mu \mathrm{g}$ of NP $\left(\mathrm{TiO}_{2}\right.$ or $\left.\mathrm{TiO}_{2} @ 5 \% \mathrm{Gd}\right)(\mathrm{n}=4)$, or $150 \mu \mathrm{g}$ of PS-NP (PS-TiO ${ }_{2}$ or PS $\left.\mathrm{TiO}_{2} @ 5 \% \mathrm{Gd}\right)(\mathrm{n}=6)$, for 24 hours before irradiation. The number of live cells was evaluated by manual cell counting after a further 24 hours. All data are normalized to the unirradiated cell-only control that is set to $100 \%$. Data are presented as mean \pm standard deviation. Significance was tested using a two-tailed t-test $(* * * P<0.005)$.

Abbreviations: NPs, nanoparticles; PS, polystyrene.

interacts with repair enzymes, antioxidant enzymes and other antioxidant compounds, which could lead to modulation of ROS production. However, in our study, there was no further decrease in cell number in the presence of the doped radiosensitizer NPs incubated with $\mathrm{CoCl}_{2}$, after irradiation (compared to the same samples without $\mathrm{CoCl}_{2}$ ) in either cell line. This could be due to a threshold in the amount of ROS that can be generated in the cells having been reached such that the presence or absence of $\mathrm{CoCl}_{2}$ did not further affect cell death. The iron-chelator DFO is also used as a hypoxia mimetic, and while apoptosis proceeds via a mitochondrialdependent pathway, it is probably that the initiating signal pathway is different to that of $\mathrm{CoCl}_{2}{ }^{22}$ The presence of DFO does not impact upon surviving cell numbers, either in unirradiated or in irradiated samples. It would be expected that under hypoxic conditions, irradiation would be less effective, and this would result in less cell death. However, at the levels of DFO used, this is not the case. With the addition of titania NPs in the presence of DFO, there was no decrease in cell number. Interestingly though, the presence of DFO prevented the expected increase in efficacy in the presence of doped titania NPs. This may suggest that DFO is not

Table I Summary of size and crystal phase of NPs

\begin{tabular}{lll}
\hline Sample & Crystal phase & Size, $\mathbf{n m}$ \\
\hline 5 at\% $\mathrm{Gd}-\mathrm{TiO}_{2}$ fresh & Anatase & $7.9(8)$ \\
& Rutile & II.I (2) \\
5 at\% $\mathrm{Gd}-\mathrm{TiO}_{2}$ fired & Anatase & $7.9(7)$ \\
& Rutile & II.7 (2) \\
\hline
\end{tabular}

Abbreviation: NPs, nanoparticles. acting as a hypoxia mimetic but simply as an iron chelating agent. It is therefore possible that under normal conditions the generation of ROS from doped titania is upregulated via a Fenton-type reaction.

Due to the differing results obtained with the hypoxia mimetics and their very specific mode of action, the action of the NPs was investigated under true hypoxia. During radiotherapy, there will be effects on proliferation and cell cycle progression, but the dominant effect of oxygen is modification of radiation-induced DNA damage decreasing its repairability, and therefore, low oxygen concentrations can result in a decrease in efficiency of radiation in inactivating cells. During our experiments, the cells were pre-incubated in hypoxic conditions, and the experiment and recovery period also subjected to the same oxygenic conditions. Although it has been demonstrated that the dominant effect of oxygen on radiosensitivity requires its presence during or within milliseconds of irradiation, the overall response is likely to be modulated to some degree by the presence or absence of oxygen effecting the response of a cell to the radiationinduced damage and background levels of damage caused by oxidative stress. Post-irradiation hypoxia has been shown to eliminate potentially lethal damage recovery (PLDR) in cells irradiated under hypoxia. However, when returned to euoxic conditions, the inhibition of PLDR by hypoxia was relieved..$^{23}$

Other metal oxides have been shown to have therapeutic activity in cancer cells under both normoxic and hypoxic conditions, although they are not activatable, and therefore lack an element of control. CuO NPs have been shown to generate ROS in lung A549 cells by ROS generation, cell cycle arrest and caspase-independent programmed necrotic death. In the same cell line, $\mathrm{Fe}_{2} \mathrm{O}_{3}$ NPs showed poly [ADPribose] polymerase 1 (PARP1)-mediated apoptosis. ${ }^{24}$ For a general review of antitumor activities of metal oxide NPs refer the study by Vinardell and Mitjans. ${ }^{25}$

Here it was shown that irradiation did not result in any significant reduction in cell numbers in cells incubated with either of the titania NP controls. However, the gadoliniumdoped titania NPs still showed a significant increase in cell death upon irradiation. This indicates that the doped titania NPs would be effective as radiosensitizers even under the hypoxic conditions seen in tumor cells.

\section{Synthesis of composite embolization particle}

To add to the utility of the doped titania NPs, a composite embolization microparticle was prepared in which the surface 
of bland embolic PS microparticles was coated with the radiosensitizer NPs. A number of methods were attempted for the attachment of the NPs to achieve good coverage of the microparticles. The first method was a one-pot method that used methacryloxypropyl trimethoxysilane (MS) to anchor the titania onto the surface of the PS spheres during the course of the microparticle polymerization reaction. However, we found that the MS coating inhibited the UV photoactivity of the titania radiosensitizer NPs and by extrapolation the ability to generate ROS by X-ray excitation (data not shown). A second method used the positively charged polyelectrolyte poly diallylmethylammonium chloride (PDADMAC) to electrostatically bind the titania NPs onto the surface of preprepared PS spheres. A reasonable coverage could be attained, but there was concern that the titania NPs could detach from the PS spheres and be released within the body. A previous study has shown that enzymatic degradation of a poly vinyl galactose ester-co-methacryloxyethyl trimethylammonium chloride (PGEDMC)/Hb polyelectrolyte film released $80 \%$ of the encapsulated fluorescein isothiocyanate. ${ }^{26}$ In the context of our NPs, enzymes in the blood stream could potentially cause the degradation of the PDADMAC electrolyte and release the titania NPs from the surface of embolic particles.

The final and most successful method for producing the PS-NP particles made use of a sintering method. Pre-prepared PS spheres were suspended in a bath of titania and then heated to $\geq 165^{\circ} \mathrm{C}$, the glass transition temperature of the PS spheres. Sintering the PS titania mixture at $165^{\circ} \mathrm{C}$ resulted in $~ 70 \%$ microparticle coverage with the titania NP, while increasing the sintering temperature to both $200^{\circ} \mathrm{C}$ and $230^{\circ} \mathrm{C}$ increased the coverage to almost $100 \%$ (Figure 6). It was important to maintain the sintering temperature $<260^{\circ} \mathrm{C}$, at which point the PS starts to degrade (data not shown). It was also desirable to maintain the firing time and temperature to a minimum since the crystal structure of the titania NPs may be adversely affected. The ability of the doped titania NPs and PS-NP embolic particles to inhibit cell proliferation was tested in vitro on the RD cell line. There was a significant decrease of $56.9 \% \pm 11.4 \%(P \leq 0.005)$ in the number of live cells for cells treated with the $\mathrm{TiO}_{2} @ 5 \% \mathrm{Gd}$ radiosensitizer NPs, compared to control cells (which were not incubated with NPs), but received the same dose of irradiation. There was also a very significant difference in the number of surviving cells between cells incubated with the $\mathrm{TiO}_{2} @ 5 \% \mathrm{Gd}$ radiosensitizer and either unirradiated or irradiated with $3 \mathrm{~Gy}$. This is the first time that a radiosensitizing embolic particle has been demonstrated, which is inert without radiation but which can be activated using X-rays to enhance cell kill.

\section{Conclusion}

The radiosensitizer embolization particles shown herein are a proof of concept and may be even further modified for greater utility. We have previously discussed the range of sizes of tumor vessels in Morrison et al, ${ }^{12}$ and the size of the bland embolization particle may be altered with ease to provide the maximal size for occlusion of the vessel. Furthermore, multimodal embolization particles may be created by the addition of fluorescent markers or MRI contrast agents into the center of the microparticles in addition to the modification of the surface to generate a radiosensitizer. The microparticles can also incorporate imaging agents such as fluorophores or heavy metals such as tantalum as X-ray contrast agents (non-magnetic so allows patient to undergo MRI) or combination with chemoembolization (a mixture of mesoporous silica NPs and titania NPs). ${ }^{8,12}$

\section{Acknowledgments}

The authors would like to thank Anna Hiraoka for assistance with cell experiments. MJRS wishes to thank Luke Bird for his assistance and help with X-ray irradiation experiments. RAM is funded by RCUK Digital Economy Programme grant number EP/G036861/1 (Oxford Centre for Doctoral Training in Healthcare Innovation). HET would like to thank Williams Fund for ongoing support. This work was in part funded by a TSB/EPSRC grant for "Nanoscale technology enabled healthcare: building the supply chain".

\section{Disclosure}

HET has submitted a patent application regarding this work and is co-founder of Xerion Healthcare. The other authors report no conflicts of interest in this work.

\section{References}

1. Townley HE, Rapa E, Wakefield G, Dobson P. Nanoparticle augmented radiation treatment decreases cancer cell proliferation. Nanomedicine. 2012;8(4):526-536.

2. Townley HE, Kim J, Dobson PJ. In vivo demonstration of enhanced radiotherapy using rare earth doped titania nanoparticles. Nanoscale. 2012;4(16):5043-5050.

3. Penfield JG, Reilly RF. What nephrologists need to know about gadolinium. Nat Clin Pract Nephrol. 2007;3(12):654-668.

4. Joiner MC, van der Kogel A. Basic Clinical Radiobiology. 4th ed. Boca Raton, FL: CRC Press; 2009.

5. Adams GE. Hypoxic cell sensitizers for radiotherapy. In: Becker FF, editor. Cancer. ed 6 ed. New York, NY: Plenum Press; 1977:181-223.

6. Wardman P. Chemical radiosensitizers for use in radiotherapy. Clin Oncol (R Coll Radiol). 2007;19(6):397-417.

7. Kaanders JH, Bussink J, van der Kogel AJ. Clinical studies of hypoxia modification in radiotherapy. Semin Radiat Oncol. 2004;14(3): 233-240.

8. Morrison R, Gardiner C, Evidente A, Kiss R, Townley H. Incorporation of ophiobolin A into novel chemoembolization particles for cancer cell treatment. Pharm Res. 2014;31(10):2904-2917. 
9. Ihara H, Kubota S, Uchimura A, et al. A facile preparation method for self-assembled monolayers with silica particles on polystyrene-based microspheres. Mater Chem Phys. 2009;114:1-5.

10. Okail MS. Cobalt chloride, a chemical inducer of hypoxia-inducible factor- $1 \alpha$ in U251 human glioblastoma cell line. J Saudi Chem Soc. 2010;2:197-201.

11. Pratsinis SE. Flame aerosol synthesis of ceramic powders. Prog Energy Combust Sci. 1998;24:197-219.

12. McNeil S, editor. Characterization of Nanoparticles Intended for Drug Delivery. Methods in Molecular Biology. Vol. 697. Berlin: Springer; 2011.

13. Morrison R, Thompson J, Bird L, Hill M, Townley HE. Synthesis and characterization of polystyrene embolization particles doped with tantalum oxide nanoparticles for X-ray contrast. J Mater Sci Mater Med. 2015;26(8):218.

14. Wegner K, Schimmöller B, Thiebaut B, Fernandez C, Rao T. Pilot plants for industrial nanoparticle production by flame spray pyrolysis. KONA Powder Part J. 2011;29:251-265.

15. Tweedle MF. Physicochemical properties of gadoteridol and other magnetic resonance contrast agents. Invest Radiol. 1992;27(suppl 1): S2-S6.

16. Caille JM, Lemanceau B, Bonnemain B. Gadolinium as a contrast agent for NMR. AJNR Am J Neuroradiol. 1983;4(5):1041-1042.

17. Nagaraja TN, Croxen RL, Panda S, et al. Application of arsenazo III in the preparation and characterization of an albumin-linked, gadoliniumbased macromolecular magnetic resonance contrast agent. J Neurosci Methods. 2006;157(2):238-245.

18. Jeynes JCG, Jeynes C, Palitsin V, Townley HE. Direct quantification of rare earth doped titania nanoparticles in individual cells. Nanotechnology. 2016;27(28):285103.
19. Rockwell S, Dobrucki IT, Kim EY, Marrison ST, Vu V. Hypoxia and radiation therapy: past history, ongoing research, and future promise. Curr Mol Med. 2009;9(4):442-458.

20. An WG, Kanekal M, Simon MC, Maltepe E, Blagosklonny MV, Neckers LM. Stabilization of wild-type p53 by hypoxia-inducible factor 1a. Nature. 1998;392(6674):405-408.

21. Gault N, Sandre C, Poncy JL, Moulin C, Lefaix JL, Bresson C. Cobalt toxicity: chemical and radiological combined effects on HaCaT keratinocyte cell line. Toxicol In Vitro. 2010;24(1):92-98.

22. Guo M, Song L-P, Jiang Y, Liu W, Yu Y, Chen G. Hypoxia-mimetic agents desferrioxamine and cobalt chloride induce leukaemic cell apoptosis through different hypoxia-inducible factor 1-a independent mechanisms. Apoptosis. 2006;11:67-77.

23. Rao BS, Hopwood LE. Effect of hypoxia on recovery from damage induced by heat and radiation in plateau-phase $\mathrm{CHO}$ cells. Radiat Res. 1985;101(2):312-325.

24. Pandey N, Dhimam S, Srivastava T, Majumder S. Transition metal oxide nanoparticles are effective in inhibiting lung cancer cell survival in the hypoxic tumour microenvironment. Chem Biol Interact. 2016; 254:221-230.

25. Vinardell MP, Mitjans M. Antitumour activities of metal oxide nanoparticles. Nanomaterials. 2015;5(2):1004-1021.

26. Zhang RR, Wu CL, Tong LL, Tang B, Xu QH. Multifunctional coreshell nanoparticles as highly efficient imaging and photosensitizing agents. Langmuir. 2009;25(17):10153-10158.
International Journal of Nanomedicine

\section{Publish your work in this journal}

The International Journal of Nanomedicine is an international, peerreviewed journal focusing on the application of nanotechnology in diagnostics, therapeutics, and drug delivery systems throughout the biomedical field. This journal is indexed on PubMed Central, MedLine, CAS, SciSearch ${ }^{\circledR}$, Current Contents ${ } /$ Clinical Medicine,

\section{Dovepress}

Journal Citation Reports/Science Edition, EMBase, Scopus and the Elsevier Bibliographic databases. The manuscript management system is completely online and includes a very quick and fair peer-review system, which is all easy to use. Visit http://www.dovepress.com/ testimonials.php to read real quotes from published authors. 